\title{
SÍNTESE ENZIMÁTICA DO CAPRILATO DE ISOPENTILA UTILIZANDO ÓLEO FÚSEL COMO MATÉRIA- PRIMA
}

\author{
Renata N. Vilas Bôas, Francisco C. Biaggio*, Domingos S. Giordani e Heizir F. de Castro
}

Departamento de Engenharia Química, Escola de Engenharia de Lorena, Universidade de São Paulo, 12602-810 Lorena - SP, Brasil

Recebido em 16/11/2016; aceito em 31/01/2017; publicado na web em 24/03/2017

\begin{abstract}
ENZYMATIC SYNTHESIS OF ISOPENTYL CAPRYLATE USING FUSEL OIL AS FEEDSTOCK. Four commercial lipase preparations immobilized by covalent attachment on epoxy-polysiloxane- $\beta$-cyclodextrin were tested as potential biocatalysts to mediate the esterification reaction of isopentanol with caprylic acid in solvent-free medium. Among them, the immobilized lipase from Rhizopus oryzae was the most active biocatalyst, attained ester conversion higher than $80 \%$ in $24 \mathrm{~h}$, being selected for subsequent tests using fusel oil as source of isopentanol. An experimental design was performed and the analysis of the results revealed that the formation of the isopentyl caprylate was strongly influenced by the variable molar ratio at $95 \%$ of confidence level. The proposed mathematical model allowed predicting that the excess of caprylic acid (molar ratio fusel oil to acid of 1:1.5) and reaction temperature of $45^{\circ} \mathrm{C}$ favor the reaction to attain high ester conversion. Sensory evaluation of the flavors profile in relation to all the components involved in the reaction (caprylic acid, fusel oil and esters) showed that the formed esters had distinct aromas from the starting materials, confirming that the changes in flavors occurred before and after esterification reactions.
\end{abstract}

Keywords: isopentyl caprylate; immobilized lipase; fusel oil; optimization; esterification.

\section{INTRODUÇÃO}

Entre os diversos subprodutos gerados pela Indústria Sucroalcooleira, o óleo fúsel apresenta amplo potencial de reaproveitamento devido sua composição rica em alcoóis superiores e elevado volume gerado (120 milhões de litros/ ano). ${ }^{1}$

Apesar do seu aproveitamento não atuar diretamente na redução do custo final do álcool, sua utilização como insumo nas indústrias de transformação certamente representa um importante passo para aumentar a eficiência global da produção industrial do etanol. ${ }^{2}$ Atualmente, a taxa de recuperação do óleo fúsel é de apenas $25 \%$ do total produzido no país, ou seja, 30 milhões de litros/ ano. ${ }^{3}$ Possíveis alternativas para o aproveitamento deste subproduto incluem a produção de alcoóis superiores por destilação fracionada, ${ }^{4}$ e síntese de ésteres por via química ou biotecnológica..$^{5-7}$

Ésteres são componentes importantes de aromas naturais e contribuem na formação e acentuação dos aromas em diversos alimentos..$^{8-11}$ Com a demanda crescente de produtos naturais, a indústria de alimentos está interessada no uso da rota biotecnológica para produção de ésteres aromatizantes. ${ }^{11}$ Desta forma, é crescente o interesse da aplicação de catalisadores bioquímicos em síntese orgânica, ${ }^{8-10}$ entre os quais especial atenção tem sido dedicada às enzimas lipolíticas (lipases e esterases), em função da elevada atividade catalítica exibida em diversos meios não convencionais., ${ }^{9,10}$

A síntese catalisada por lipases (glicerol éster hidrolases EC 3.1.1.3) de mais de 50 ésteres de aromatizantes já foi descrita na literatura ${ }^{8,11} \mathrm{e}$, em princípio, a reação pode ser conduzida em meio reacional constituído de álcool e ácido carboxílico em presença ou ausência de solventes, resultando em produtividades elevadas e rendimentos quantitativos..$^{910}$ Entretanto, são escassos os trabalhos encontrados na literatura referentes à aplicação de lipases na biotransformação dos alcoóis presentes (etanol, 13\%; butanol, 15\%; isobutanol, 10\%; isopentanol, 51\%) no óleo fúsel em seus ésteres respectivos. ${ }^{12-16}$ Este fato pode estar associado às dificuldades técnicas envolvidas quando misturas de alcoóis são usadas

*e-mail: biaggio@dequi.eel.usp.br em reações de esterificação direta, como competição entre dois ou mais nucleofílicos pelo mesmo sítio ativo da enzima e o elevado teor de água presente nesse material que exige a aplicação de técnicas especiais de desidratação por meio do emprego de sais desidratantes ou peneira molecular para tornar adequado este tipo de substrato às condições de catálise mediada por lipases (baixo teor de água $<500$ ppm). ${ }^{9,17}$ Além disso, a presença de teores elevados de alcoóis secundários pode acarretar uma complexidade adicional, tendo em vista que a esterificação de álcoois secundários é fortemente dependente da fonte de lipase e do tamanho da cadeia do ácido carboxílico. ${ }^{7,9}$ Os rendimentos de esterificação tendem a diminuir com ácidos de tamanho de cadeia curta $^{7}$; sendo os resultados mais baixos obtidos com o ácido acético. ${ }^{15}$ Desta forma, a seleção do doador do grupo acila é um fator crucial para uma transformação eficiente do substrato por catálise enzimática. Estudos reportados na literatura demonstram elevados rendimentos de esterificação (> 95\%), utilizando ácidos de cadeia carbônica longa (número de carbonos superior a 12) como doador do grupo acila. ${ }^{13,14,18,19}$

No presente estudo foi proposto avaliar ácido carboxílico de cadeia média (ácido caprílico) como doador do grupo acila na produção de ésteres aromatizantes naturais a partir de óleo fúsel. Em função dos resultados satisfatórios obtidos anteriormente por Santos et al. ${ }^{20}$ optou-se pela manutenção de sistemas reacionais isentos de solventes. Tais sistemas apresentam inúmeras vantagens, entre as quais se destacam: i) evita problemas de separação, de toxicidade e flamabilidade dos solventes orgânicos e ii) reduz o custo do produto final. Além disso, a eliminação de solventes é particularmente interessante nas indústrias alimentícias, nas quais existem rigorosas regulamentações para o seu uso. ${ }^{20}$

Os experimentos foram realizados utilizando fonte de lipase selecionada para esterificação de alcoóis secundários, adotando a metodologia de planejamento estatístico que possibilita verificar a influência das variáveis e suas interações no rendimento de um determinado processo com grande economia de tempo, material e recursos. ${ }^{21}$ Adicionalmente ao controle dos parâmetros de processo foi também utilizado um sensor olfativo artificial para detecção dos compostos voláteis presentes nos produtos formados, utilizando 
metodologia que permite correlacionar o perfil sensorial das amostras de ésteres obtidas a partir das matérias-primas precursoras no sistema reacional. ${ }^{22,23}$

\section{PARTE EXPERIMENTAL}

\section{Materiais}

Foram utilizadas preparações de lipases comerciais de origem microbiana de diferentes fontes, como lipase de Rhizopus oryzae (L036P) adquirida da Biocatalysts (Cardiff, Inglaterra) e Candida rugosa (Tipo VII); Pseudomonas fluorescens e Burkholderia cepacia adquiridas da Sigma-Aldrich Chemical (St. Loius, MO, EUA). O óleo fúsel foi gentilmente fornecido pela destilaria (São Martinho S/A - Unidade Iracema, localizada em Iracemápolis - São Paulo) com composição aproximada de $65 \%$ de isopentanol, $8 \%$ de isobutanol, $0,4 \%$ de butanol, $1,5 \%$ de propanol, $10 \%$ de etanol e $15 \%$ de água. Outros reagentes utilizados foram: $\beta$-ciclodextrina (Sigma-Aldrich- $\beta C D, 97 \%$ ), tetraetilortossilicato (Sigma-AldrichTEOS, 98\%); epicloridrina (Sigma-Aldrich 99\%), ácido caprílico (Merck, 97\%), isopentanol (Merck, 99\%), heptano e hexanol (Vetec), polietilenoglicol - PEG-1.500 (Sinthy), goma arábica em pó pura (Synth), hidróxido de potássio (min. 85\%, Cromoline) e azeite de oliva com baixa acidez (Carbonell, adquirido em mercado local). Os padrões (caprilato de butila e caprilato de isopentila) para calibração do método via análise cromatográfica foram obtidos por síntese química de acordo com Urioste et al. ${ }^{24}$ Os ésteres foram purificados por destilação à pressão reduzida e as estruturas químicas confirmadas por análise de Ressonância Magnética Nuclear de Próton $\left(\mathrm{RMN}^{1} \mathrm{H}\right)$, conforme ilustrado no material suplementar (1S). Os espectros foram obtidos no aparelho Varian Mercury 300 $\mathrm{MHz}$. Os deslocamentos químicos $(\delta)$ foram referenciados pelo sinal do TMS (Tetrametilsilano $-\delta=0$ ) em $\mathrm{CDCl}_{3}$. Cada espectro foi analisado calculando-se a integração dos números relativos de hidrogênio presente na estrutura química do monoéster de ácido em 0,00-6,00 ppm.

\section{Síntese e ativação da matriz de imobilização das lipases}

$\mathrm{O}$ suporte híbrido sílica- $\beta$-ciclodextrina $\left(\mathrm{SiO}_{2}-\beta C D\right)$ foi sintetizado pela técnica sol-gel utilizando TEOS como precursor e posteriormente ativado com epicloridrina de acordo com técnica descrita por Martin et al. ${ }^{25}$ fornecendo suporte com as seguintes características texturais: área superficial específica $\left(450,5 \mathrm{~m}^{2} \mathrm{~g}^{-1}\right)$, volume específico dos poros $\left(0,36 \mathrm{~cm}^{3} \mathrm{~g}^{-1}\right)$ e diâmetro médio dos poros $32,09 \AA$.

\section{Imobilização das lipases no suporte híbrido}

A matriz epoxilada (epóxi-SiO ${ }_{2}-\beta C D$ ) foi utilizada para imobilizar as lipases de diversas fontes empregando para cada grama de suporte ativado (matéria seca) $250 \mathrm{mg}$ de lipase na sua forma livre, e $100 \mu \mathrm{L}$ de solução aquosa contendo $5 \mathrm{mg} \mathrm{mL}^{-1}$ de polietilenoglicol (massa molecular 1500). As suspensões contendo enzima e suporte foram mantidas sob agitação a $30^{\circ} \mathrm{C}$ por $2 \mathrm{~h}$, seguido de contato estático por um período adicional de $18 \mathrm{~h} \mathrm{a} 4^{\circ} \mathrm{C}$. A recuperação dos derivados imobilizados foi efetuada por filtração a vácuo, com lavagens sucessivas com hexano para remoção do excesso de umidade. ${ }^{25}$ Em seguida, os derivados imobilizados foram acondicionados em dessecador sob vácuo para redução da umidade em valores inferiores a $8 \%$. As atividades enzimáticas das lipases imobilizadas foram determinadas pelo método de hidrólise do azeite de oliva, conforme a metodologia modificada por Soares et al. ${ }^{26 .}$

\section{Tratamento do óleo fúsel}

O elevado teor de água originalmente presente no óleo fúsel foi reduzido por meio de peneiras moleculares de $0,32 \AA$ (Silicato de sódio e alumínio) tipo $13 \mathrm{X}$-BHD Chemicals. Deve ser destacado que não foi utilizada a técnica de destilação fracionada para a remoção de água presente no óleo fúsel devido ao interesse de manter a composição original da mistura dos alcoóis característico do óleo fúsel para ser utilizado como matéria-prima residual nas reações. A concentração de água presente no óleo fúsel foi reduzida de $15 \%$ para $0,1 \%$, quantificando o teor de água em titulador automático Karl Fisher (Modelo Koehler AKF5000).

\section{Síntese do caprilato de isopentila}

\section{Testes de seleção da lipase}

Testes iniciais foram direcionados para a seleção da lipase mais adequada para catalisar reações de esterificação do isopentanol com o ácido caprílico. As reações foram conduzidas em reatores fechados de $100 \mathrm{~mL}$ contendo $20 \mathrm{~mL}$ de substrato sem adição de solventes em proporção equimolar. As misturas foram incubadas com as diferentes preparações de lipase imobilizada em $\mathrm{SiO}_{2}-\beta C D$ na proporção de 350 unidades de atividade por grama de meio reacional, por um período máximo de $48 \mathrm{~h}$, com agitação magnética $(150 \mathrm{rpm})$ a $45^{\circ} \mathrm{C}$. Amostras foram retiradas durante o progresso da reação (12, 24 e $48 \mathrm{~h}$ ) para quantificação da concentração dos materiais de partida e cálculo da conversão em éster baseada no consumo do isopentanol.

\section{Planejamento fatorial}

A influência das variáveis: razão molar $\left(\mathrm{X}_{1}\right)$ e temperatura $\left(\mathrm{X}_{2}\right)$ na síntese do caprilato de isopentila a partir do óleo fúsel e ácido caprílico empregando a preparação de lipase imobilizada selecionada anteriormente foi determinada por um planejamento composto de face centrada $2^{2}$ e pontos centrais. As reações foram conduzidas em reatores fechados de $100 \mathrm{~mL}$ contendo $20 \mathrm{~mL}$ de substrato composto de óleo fúsel previamente desidratado e ácido caprílico, sem adição de solvente em razões molares entre álcool/ácido de 1:0,5 a 1:1,5 (a proporção de óleo fúsel adicionado foi calculada com base na concentração de isopentanol presente neste subproduto). As misturas foram incubadas com a preparação de lipase imobilizada, na proporção de $10 \%(\mathrm{~m} / \mathrm{m})$ em relação à massa total dos reagentes envolvidos no meio reacional, por um período máximo de $48 \mathrm{~h}$, com agitação magnética $(150 \mathrm{rpm})$ na faixa de temperatura entre 40 a 50 ${ }^{\circ} \mathrm{C}$. Todos os experimentos foram efetuados de maneira randômica. Como variável resposta foi considerada a conversão em caprilato de isopentila. Nesta série de experimentos a formação do caprilato de isobutila não foi avaliada em função da baixa concentração do isobutanol presente no óleo fusel $(\cong 8 \%)$. A análise estatística dos resultados foi realizada utilizando-se o programa Statistica versão 13.

\section{Determinação dos produtos formados e reagentes consumidos}

A formação dos produtos (caprilato de isobutila e caprilato de isopentila) e o consumo dos alcoóis (isobutanol e isopentanol) foram determinados em cromatógrafo a gás (Varian - Modelo CG 3800 Varian, Inc., Palo Alto, CA, EUA) equipado com uma coluna empacotada de aço inoxidável (80/100 mesh, 6ft, 2,0 mm ID X 1/8 OD) e detector de ionização em chama (FID). A temperatura do detector foi fixada em $230{ }^{\circ} \mathrm{C}$ e a do injetor em $190{ }^{\circ} \mathrm{C}$. Nitrogênio foi usado como gás de arraste num fluxo de $10 \mathrm{~mL} \mathrm{~min}^{-1} \mathrm{e}$ os fluxos dos gases de arraste para alimentação do detector foram: $30 \mathrm{~mL} \mathrm{~min}^{-1}$ de $\mathrm{H}_{2} \mathrm{e}$ $300 \mathrm{~mL} \mathrm{~min}^{-1}$ de ar sintético. As condições operacionais estabelecidas foram: temperatura da coluna ajustada para $60{ }^{\circ} \mathrm{C}$ durante 3 min e 
depois programada a $90{ }^{\circ} \mathrm{C}$ por 3 min numa taxa de $15{ }^{\circ} \mathrm{C} \mathrm{min}{ }^{-1} \mathrm{se}-$ guida de aquecimento até $120^{\circ} \mathrm{C}$ numa taxa de $20^{\circ} \mathrm{C} \mathrm{min}^{-1} \mathrm{e}$ mantida em $120^{\circ} \mathrm{C}$ por $6 \mathrm{~min}$. Como padrão interno foi utilizado $n$-hexanol $\left(50 \mathrm{~g} \mathrm{~L}^{-1}\right)$ em heptano. A coleta e análise de dados foram realizadas utilizando os dados gerados pelo Sistema Galaxie versão 1.9. O teor de ácido caprílico foi determinado por titulação de alíquotas diluídas em etanol, empregando solução alcoólica de $\mathrm{KOH} 0,05 \mathrm{~mol} \mathrm{~L}^{-1}$ e fenolftaleína como indicador.

\section{Análise sensorial por nariz eletrônico}

A coleta de dados efetuada pelo nariz eletrônico (modelo Cyranose 320TM, marca Smiths Detection, fabricado por Sensigent INC, EUA) se baseia na sucção da amostra pelo headspace e exposição a um conjunto de 32 sensores que, em consequência, têm alteradas as suas resistências elétricas, as quais são registradas, formando o perfil olfativo da amostra. Para a caracterização dos componentes estudados, utilizou-se a vazão de $180 \mathrm{~cm}^{3} \mathrm{~min}^{-1}$ para a sucção de ar e de $50 \mathrm{~cm}^{3} \mathrm{~min}^{-1}$ para o headspace, com tempos de $10 \mathrm{~s}$ e $60 \mathrm{~s}$, respectivamente. Foram acondicionados $5 \mathrm{~mL}$ de amostra para cada componente (ácido caprílico, óleo fúsel e ésteres formados na síntese) separadamente em 10 recipientes e realizadas 10 leituras para cada amostra. O programa utilizado para estabelecer as condições de análise foi o PCnose. O método estatístico adotado para análise dos resultados foi o PCA (Principal Componentes Analysis), que permite a redução do perfil olfativo a três parâmetros de maior significância das alterações produzidas nos sensores, possibilitando a geração de um gráfico tridimensional para visualização do resultado.

\section{RESULTADOS E DISCUSSÃO}

\section{Seleção da lipase para síntese do caprilato de isopentila}

A imobilização das quatro fontes de lipase Candida rugosa, Burkholderia cepacia, Pseudomonas fluorescens e Rhizopus oryzae no suporte híbrido $\mathrm{SiO}_{2}-\beta C D$ forneceu elevada eficiência (> 60\%), demonstrando que o procedimento de imobilização foi efetuado com sucesso, resultando em derivados imobilizados com elevadas atividades hidrolíticas variando na faixa de $2020 \mathrm{Ug}^{-1}$ e $3714 \mathrm{U} \mathrm{g} \mathrm{g}^{-1}$ (Tabela 1). O teor de água dos derivados imobilizados foi inferior a $8 \%$ visando reduzir a influência da água no meio reacional.

Tabela 1. Atividade enzimática $\left(\mathrm{Ug}^{-1}\right)$ e teor de umidade das preparações de lipases imobilizadas em $\mathrm{SiO}_{2}-\beta C D$

\begin{tabular}{lcc}
\hline Enzima & $\begin{array}{c}\text { Atividade catalítica* } \\
\left(\mathbf{U g}^{-1}\right)\end{array}$ & $\begin{array}{c}\text { Teor de água } \\
(\%)\end{array}$ \\
\hline Candida rugosa & $2802 \pm 43$ & 4,94 \\
Pseudomonas fluorescens & $2020 \pm 69$ & 7,29 \\
Burkholderia cepacia & $2090 \pm 70$ & 6,82 \\
Rhizopus oryzae & $3714 \pm 35$ & 7,68 \\
\hline
\end{tabular}

"Método de hidrólise do azeite de oliva (emulsão 50\%; pH 7,0; temperatura $\left.37^{\circ} \mathrm{C}\right)$.

Para selecionar o derivado imobilizado mais adequado na formação de ésteres secundários foram mantidas fixas as condições reacionais, incluindo o carregamento catalítico (350 unidades de atividade por grama de meio reacional). Os valores de conversão em éster para diferentes tempos de incubação (12, 24 e 48h) dispostos na Figura 1 indicam que todas as lipases testadas apresentaram potencial para catalisar a reação de esterificação, alcançando conversões superiores a $70 \%$ em 24 h de reação.
As lipases de Pseudomonas fluorescens e de Burkholderia cepacia foram menos eficientes. Entretanto, ao usar a preparação de P. fluorescens, obteve-se conversão mais elevada alcançando valores médios de $83,78 \% \pm 7,43$ em 48 h. Verificou-se que a lipase de $B$. cepacia, nas condições testadas, apresentou tendência de hidrolisar o éster após 24 h de reação, sendo a conversão em éster reduzida de $77,47 \% \pm 1,98$ para $70,19 \% \pm 7,76$.

Conversões similares foram obtidas pelas lipases de Candida rugosa e Rhizopus oryzae, que forneceram valores de conversão superiores a $80 \%$ em 24 h de reação. O progresso da reação catalisada por $R$. oryzae confirmou a potencialidade desta lipase para mediar reações em meio orgânico (esterificação e interesterificação), conforme anteriormente reportado. ${ }^{27}$

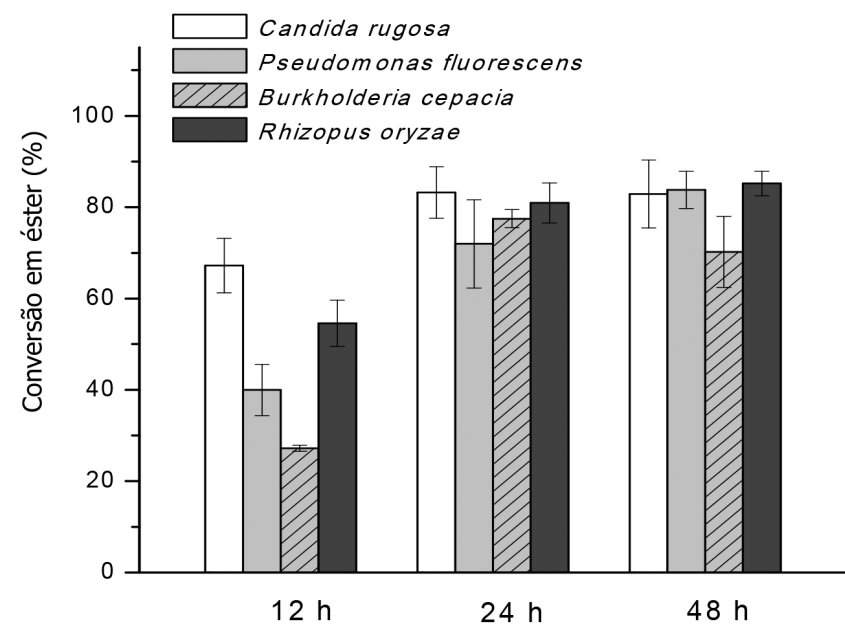

Figura 1. Conversão em éster durante a síntese do caprilato de isopentila mediada por diferentes fontes de lipases imobilizadas em $\mathrm{SiO}_{2}-\beta C D$ nos tempos 12, 24 e 48 h (condições: temperatura $=45^{\circ} \mathrm{C}$, razão equimolar álcool/ ácido e meio isento de solvente)

Desta forma, selecionou-se esta preparação de lipase para testes subsequentes. Adicionalmente esta lipase na forma imobilizada apresentou elevado tempo de meia-vida quando utilizada em processos

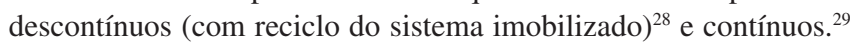
Propriedades adicionais da lipase de $R$. oryzae imobilizada em $\mathrm{SiO}_{2}$ $\beta C D$ revelaram os seguintes parâmetros na hidrólise do azeite de oliva: $\mathrm{K}_{m}=852 \mathrm{mmol} \mathrm{L}^{-1}, \mathrm{~V}_{\max }=52961 \mu \mathrm{mol} \mathrm{L}^{-1} \mathrm{~g}^{-1} \mathrm{~min}^{-1}$ e estabilidade térmica a $50{ }^{\circ} \mathrm{C}=8,0 \mathrm{~h}$.

\section{Otimização da síntese de caprilato de isopentila}

Tendo selecionado a lipase $R$. oryzae como a fonte enzimática mais efetiva na síntese de caprilato de isopentila, testes subsequentes foram efetuados substituindo o isopentanol de grau analítico por óleo fúsel. As condições testadas na síntese de ésteres a partir do isopentanol presente no óleo fúsel com o ácido caprílico estão apresentadas na Tabela 2, juntamente com os resultados obtidos expressos em conversão em éster para diferentes tempos de incubação (24 e 48 h).

Verifica-se, na Tabela 2, que utilizando ácido caprílico como doador do grupo acila, o biocatalisador selecionado foi efetivo na formação de ésteres em meio isento de solventes, alcançando elevadas conversões (> 50\%) nas primeiras $24 \mathrm{~h}$ de reação (ensaios 2 , 4, 6, 7, 8, 9, 10 e 11). Entretanto, constatou-se que para substratos contendo excesso de álcool (razão molar álcool: ácido=1:0,5) foram obtidas conversões inferiores a $20 \%$, independente da temperatura de incubação (ensaios 1, 3 e 5). Em 48 h de reação, observa-se que apenas as reações conduzidas em substratos contendo excesso de 
Tabela 2. Matriz experimental e resultados obtidos no planejamento composto de face centrada $2^{2}$ utilizado para determinar as condições otimizadas da reação de esterificação do ácido caprílico com óleo fúsel catalisada pela lipase de $R$. oryzae imobilizada em $\mathrm{SiO}_{2}-\beta C D$

\begin{tabular}{|c|c|c|c|c|c|c|}
\hline \multirow{2}{*}{ Ensaio } & \multicolumn{2}{|c|}{ Variável codificada } & \multicolumn{2}{|c|}{ Variável real } & \multicolumn{2}{|c|}{$\begin{array}{c}\text { Variável resposta } \\
\text { (conversão em éster \%) }\end{array}$} \\
\hline & $\mathbf{X}_{1}$ & $\mathbf{X}_{2}$ & $\begin{array}{l}\text { Razão Molar } \\
\text { (álcool: ácido) }\end{array}$ & $\begin{array}{c}\text { Temperatura } \\
\left({ }^{\circ} \mathbf{C}\right)\end{array}$ & $24 \mathrm{~h} *$ & $48 h$ \\
\hline 1 & -1 & -1 & $1: 0,5$ & 40 & 17,10 & 33,77 \\
\hline 2 & +1 & -1 & $1: 1,5$ & 40 & 74,41 & 85,18 \\
\hline 3 & -1 & +1 & $1: 0,5$ & 50 & 13,60 & 29,82 \\
\hline 4 & +1 & +1 & $1: 1,5$ & 50 & 89,23 & 88,89 \\
\hline 5 & -1 & 0 & $1: 0,5$ & 45 & 17,10 & 33,77 \\
\hline 6 & +1 & 0 & $1: 1,5$ & 45 & 85,86 & 90,91 \\
\hline 7 & 0 & -1 & $1: 1$ & 40 & 58,36 & 62,78 \\
\hline 8 & 0 & +1 & $1: 1$ & 50 & 62,15 & 62,46 \\
\hline 9 & 0 & 0 & $1: 1$ & 45 & 63,77 & 63,77 \\
\hline 10 & 0 & 0 & $1: 1$ & 45 & 66,17 & 63,17 \\
\hline 11 & 0 & 0 & $1: 1$ & 45 & 57,19 & 61,98 \\
\hline
\end{tabular}

*Valores considerados para a análise estatística.

ácido (razão molar álcool: ácido=1:1,5) alcançaram conversões superiores a $85 \%$ (ensaios 2, 4 e 6), independente da temperatura de incubação. Os dados obtidos indicam, de maneira geral, que o excesso de ácido garante a formação do complexo enzima-grupo acila para posterior reação com o álcool, conduzindo assim à formação do éster, e reduzindo, desta forma, a competição entre os aceptores, parâmetro essencial para a cinética de uma reação de esterificação. ${ }^{9,10}$ Isto sugere que a síntese de caprilato de isopentila catalisada pela lipase $R$. oryzae imobilizada em $\mathrm{SiO}_{2}-\beta C D$ pode ser limitada pela concentração de ácido caprílico, sugerindo a necessidade de se trabalhar com excesso deste reagente.

As baixas conversões obtidas nas reações contendo excesso de álcool podem ser também correlacionadas com a polaridade global do sistema reacional determinada pelo parâmetro $\log P$, definido como o coeficiente de partição em um sistema bifásico padrão octanol/água para compostos orgânicos. ${ }^{30}$ De acordo com a literatura, os valores tabulados de $\log P$ para o isopentanol é da ordem de 1,28 , enquanto o ácido caprílico possui um valor $=3,05$. Desta forma, nos sistemas reacionais contendo excesso de óleo fúsel, a polaridade mais elevada do substrato pode modificar a interação do álcool com a água essencial ao redor da enzima limitando a migração do ácido para a fase sólida da enzima, resultando na redução da atividade da enzima. ${ }^{7,9}$

Esses resultados estão de acordo com o descrito por Sun et al., ${ }^{7}$ referente aos efeitos adversos causados pela elevada polaridade do óleo fúsel quando adicionado em meios reacionais, notadamente para meios contendo óleo fúsel em excesso.

Considerando os valores obtidos ao final de $24 \mathrm{~h}$ de reação, o efeito individual dos fatores experimentais e de suas interações sobre a conversão em éster foi avaliada estatisticamente utilizando o programa Statistica versão 13 (Tabela 3).

As estimativas dos efeitos, erros-padrão, valor de $p$ e valor de $\mathrm{t}$ para a resposta analisada mostraram que as variáveis linear $\left(\mathrm{X}_{1}\right)$ e quadrática $\left(\mathrm{X}_{1}^{2}\right)$ (razão molar) foram estatisticamente significativas para um nível de confiança de $95 \%$, indicando que excesso de ácido ocasiona maior consumo de álcool e consequentemente maior formação do éster. Verifica-se ainda que o efeito da variável temperatura $\left(\mathrm{X}_{2}\right)$ não foi estatisticamente significativo ao nível de $95 \%$ de confiança, sugerindo que esta variável não exerce influência significativa na formação do éster. Entretanto, a interação $\mathrm{X}_{1}$ e $\mathrm{X}_{2}$ foi estatisticamente significativa para um nível de confiança de $95 \%$, demonstrando que a
Tabela 3. Estimativa dos efeitos para a conversão em éster de acordo com o planejamento fatorial $2^{2}$ com face centrada para um nível de confiança $95 \%$

\begin{tabular}{lcccc}
\hline Variável & Efeito & $\begin{array}{c}\text { Erro } \\
\text { Padrão }\end{array}$ & Valor t & $\boldsymbol{p}$ \\
\hline Média & 62,53 & 1,56 & 39,96 & $0,0000^{*}$ \\
$\left(\mathrm{X}_{1}\right)$ Razão Molar & 67,23 & 2,49 & 26,99 & $0,0000^{*}$ \\
$\left(\mathrm{X}_{1}^{2}\right)$ Razão Molar & $-22,60$ & 3,83 & $-5,89$ & $0,0019^{*}$ \\
$\left(\mathrm{X}_{2}\right)$ Temperatura & 5,03 & 2,49 & 2,02 & 0,0990 \\
$\left.\mathrm{X}_{2}^{2}\right)$ Temperatura & $-5,05$ & 3,83 & $-1,31$ & 0,2442 \\
$\mathrm{X}_{1} \cdot \mathrm{X}_{2}$ & 9,16 & 3,05 & 3,00 & $0,0299^{*}$ \\
\hline
\end{tabular}

${ }^{*} p$ : efeitos significativos para valores de $\mathrm{p}<0,05$.

temperatura quando combinada com a razão molar exerce influência significativa na conversão em éster (\%).

Os efeitos principais para a conversão foi ajustado por análise de regressão múltipla para um modelo polinomial e a melhor função ajustada pode ser descrita pela Equação 1, em que: Y é a variável resposta (conversão em ester \%) e $\mathrm{X}_{1}$ e $\mathrm{X}_{2}$ representam os valores codificados para razão molar e temperatura, respectivamente.

$$
Y=62,53+33,61 X_{1}-11,30 X_{1}^{2}+4,58 X_{1} X_{2}
$$

A significância estatística dos efeitos principais e da interação dos fatores sobre a formação do caprilato de isopentila foi realizada por análise de variância, como mostrado na Tabela 4.

Por meio dos resultados obtidos (significância de $95 \%$ do modelo $p<0,05)$, pode-se concluir que há relação entre as variáveis e que análise de variância proporcionou um bom ajuste do modelo aos dados experimentais. Verifica-se ainda pelo valor de $\mathrm{R}^{2}$ de 0,9936 que a equação ajustada foi capaz de explicar $99,36 \%$ da variabilidade dos valores experimentais.

Desta forma, considera-se que o modelo estatístico obtido foi adequado para descrição da conversão em caprilato de isopentila em função da razão molar ácido/álcool e da temperatura, obtendo-se a superfície de resposta apresentada na Figura 2.

A observação da Figura 2 indica que a conversão em éster (\%) foi dependente da razão molar (álcool/ácido) e da interação 
Tabela 4. Análise de variância (ANOVA) para a variável resposta conversão em éster (\%)

\begin{tabular}{lccccc}
\hline Variável & $\begin{array}{c}\text { Soma } \\
\text { quadrática }\end{array}$ & $\begin{array}{c}\text { Grau de } \\
\text { liberdade }\end{array}$ & $\begin{array}{c}\text { Média } \\
\text { quadrática }\end{array}$ & $\mathbf{F}_{\text {cal }}$ & $\mathbf{p}<\mathbf{0 , 0 5}$ \\
\hline $\mathrm{X}_{1}$ & 6780,48 & 1 & 6780,48 & 728,71 & $0,0000^{*}$ \\
$\mathrm{X}_{1}{ }^{2}$ & 323,69 & 1 & 323,69 & 34,78 & $0,0019 *$ \\
$\mathrm{X}_{2}$ & 38,05 & 1 & 38,05 & 4,08 & 0,0990 \\
$\mathrm{X}_{2}^{2}$ & 16,19 & 1 & 16,19 & 1,74 & 0,2442 \\
$\mathrm{X}_{1} \mathrm{X}_{2}$ & 83,90 & 1 & 83,90 & 9,01 & $0,0299 *$ \\
Erro puro & 46,52 & 5 & & & \\
$\mathrm{R}^{2}$ & 0,9936 & & & & \\
\hline
\end{tabular}

F: teste estatístico de comparação da variância nos ensaios, permitindo a avaliação da qualidade do ajuste do modelo. *Significativo ao nível de significância de $95 \%(\mathrm{p}<0,05)$.

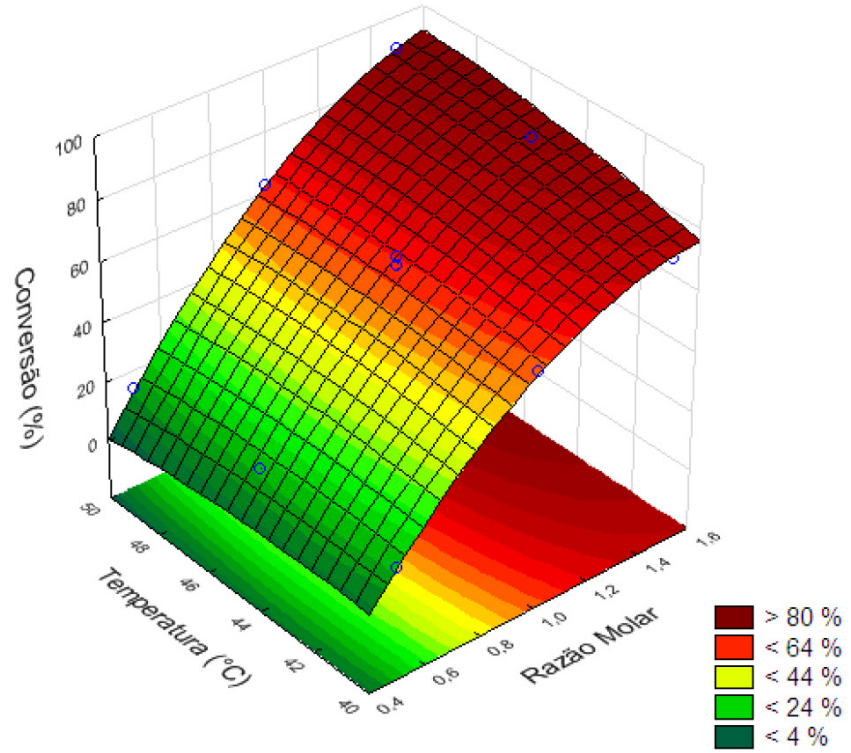

Figura 2. Superfície de resposta de acordo com a equação predita para conversão em caprilato de isopentila (\%) em função da razão molar álcool/ ácido e temperatura

temperatura com a razão molar. Portanto, com o aumento da razão molar (álcool/ácido), a conversão aumenta gradativamente. Verificase ainda que para se obter elevadas conversões (> 80\%) em $24 \mathrm{~h}$ de reação, a razão molar entre álcool e ácido deve ser maior que $1: 1,5$ e a temperatura de incubação maior que $40^{\circ} \mathrm{C}$. O experimento

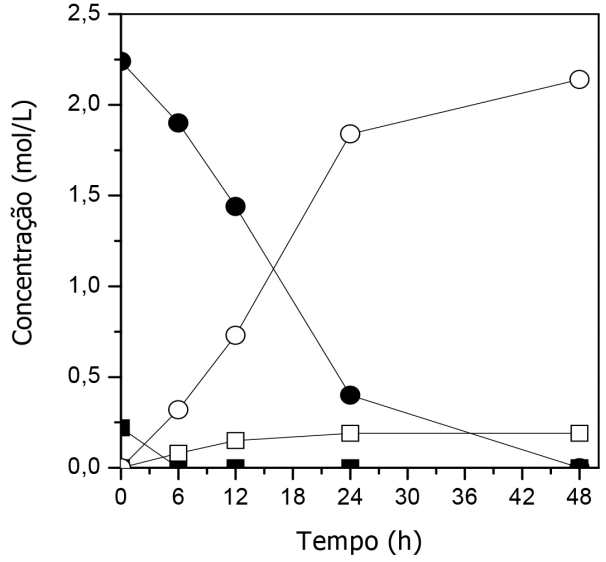

Figure 3. Perfil de consumo do isobutanol (ם) e isopentanol (@) na formação dos ésteres caprilato de isobutila $(\square)$ e caprilato de isopentila $(\bigcirc)$ na reação de esterificação do óleo fúsel com ácido caprílico nas condições estimadas pelo planejamento fatorial: razão molar (álcool/ácido) de 1:5 e temperatura de $45^{\circ} \mathrm{C}$

conduzido nas condições preditas pelo modelo (razão molar entre álcool/ácido de $1: 5$ e temperatura de $45^{\circ} \mathrm{C}$ ) indicou rápido consumo dos reagentes, atingindo conversões superiores a $82 \%$ em $24 \mathrm{~h}$ de reação, confirmando dessa forma o modelo matemático obtido (Figura 3).

Os resultados obtidos quando comparado aos dados descritos na literatura indicam comportamentos diferenciados em função da diversidade das fontes de lipases, polaridade do grupo acila, razões molares e tempo de reação (Tabela 5). A esterificação de ácidos carboxílicos com álcoois catalisada por lipase é uma estratégia comum para a acilação de álcoois primários, enquanto ainda permanece uma tarefa complexa para álcoois secundários. Neste caso específico, a seleção de um doador do grupo acila apropriado influencia a reatividade da enzima significativamente.

Nos trabalhos identificados na literatura são descritos a utilização do óleo fúsel proveniente da fermentação de milho, ${ }^{31}$ e proveniente da fermentação do caldo de cana-de-açúcar. ${ }^{12,13,32}$ Apesar da diferença entre as unidades produtoras, bem como das concentrações dos álcoois constituintes do óleo fúsel, isopentanol, etanol e isobutanol sempre se apresentaram em maior proporção.

Macedo e Pastore ${ }^{12}$ testaram cinco lipases microbianas de Geotrichum sp., Alcaligenes sp., Aspergillus sp. 1068, Aspergullus sp. 1099 e Rhizopus sp. quanto à capacidade de catalisar a síntese de ésteres formadores de aroma por esterificação em meio isento de solvente orgânico utilizando óleo fúsel como precursor. A natureza da enzima, assim como o tamanho da cadeia dos ácidos afetaram as

Tabela 5. Conversão em ésteres relatados por vários autores e no presente trabalho, obtidos pela esterificação do isopentanol proveniente do óleo fúsel com ácidos carboxílicos com lipases de diferentes fontes e sob diferentes condições reacionais

\begin{tabular}{|c|c|c|c|c|c|}
\hline Enzima & Solvente & Materiais de partida & $\begin{array}{c}\text { Conversão em éster } \\
(\%)\end{array}$ & $\begin{array}{l}\text { Tempo de reação } \\
\text { (h) }\end{array}$ & Referência \\
\hline Rhizopus oryzae & isento & ácido propílico /isopentanol & 72 & 24 & Macedo,Pastore ${ }^{12}$ \\
\hline Lipozyme TL IM & heptano & ácido láurico /isopentanol & 92 & 8 & Castro et al. ${ }^{13}$ \\
\hline Lipozyme TL IM & hexano & ácido butírico /isopentanol & 93 & 18 & Anschau et al. ${ }^{14}$ \\
\hline Novozym® 435 & isento & ácido acético /isopentanol & 75 & 8 & Guvenç et al. ${ }^{15}$ \\
\hline Candida cylindracea & hexano & $\begin{array}{l}\text { ácido butírico /isopentanol } \\
\text { ácido acético /isopentanol }\end{array}$ & $\begin{array}{l}65,8 \\
46,4\end{array}$ & $\begin{array}{l}48 \\
48\end{array}$ & Welsh; Williams $^{31}$ \\
\hline Novozym® 435 & isento & ácido oleico /isopentanol & 99,8 & 6 & Dormo et al. ${ }^{16}$ \\
\hline Rhizopus oryzae & isento & ácido caprílico/isopentanol & 82 & 24 & Este trabalho \\
\hline
\end{tabular}


conversões obtidas. Os resultados mais elevados foram obtidos na síntese do laurato de isoamila ( $88 \%$ ) e propianato de isoamila ( $72 \%$ ) utilizando a lipase de Rhizopus sp. em 24 h de incubação, seguido de $82 \%$ de conversão na síntese de acetato de isopropila por Alcaligenes sp. em 24 h de incubação. O desempenho superior reportado por De Castro et al. ${ }^{13}$ empregando um sistema reacional composto de ácido láurico e óleo fúsel (conversões de $92 \%$ em $8 \mathrm{~h}$ de reação) pode ser relacionado ao biocatalisador utilizado (Lipozyme) uma preparação de lipase de Mucor miehi imobilizada em resina de troca iônica disponível comercialmente. ${ }^{17}$ Este biocatalisador é considerado um dos mais adequados para mediar reações de esterificação devido ao levado poder do suporte em adsorver a água formada durante a reação de síntese, mantendo desta forma condição adequada de baixo teor de água no meio reacional, reduzindo a ocorrência da reação inversa de hidrólise. ${ }^{17}$

Resultados similares foram obtidos por Anschau et al. ${ }^{14}$ utilizando também Lipozyme TL IM na síntese de butirato de isopentila a partir do óleo fúsel e ácido butírico em quantidades equimolares na presença de hexano a $30^{\circ} \mathrm{C}$. Nessas condições foram relatados $93 \%$ conversão e concentração do butirato de isopentila de $1,0 \mathrm{~mol} \mathrm{~L}^{-1} \mathrm{em}$ 18 horas de reação.

Guvenç et al. ${ }^{15}$ utilizando o sistema reacional ácido acético e isopentanol reportaram resultados de conversão de 75\% (3,40 mol $\left.\mathrm{L}^{-1}\right)$ em $8 \mathrm{~h}$ na reação catalisada pela lipase imobilizada da Candida antarctica (Novozym $\left.{ }^{\circledR} 435\right)$ em meio isento de solvente, e verificaram que variável mais significativa foi a razão molar ácido/álcool $(0,2: 0,8)$. Ainda Welsh e Williams, ${ }^{31}$ reportaram produção máxima de uma mistura de éster de ácido butírico $\left(0,62 \mathrm{~mol} \mathrm{~L}^{-1}\right.$; conversão = $65,8 \%)$ e éster de ácido acético $\left(0,052 \mathrm{~mol} \mathrm{~L}^{-1}\right.$; conversões $\left.=46,4 \%\right)$ em 48 h de reação utilizando a lipase Candida cylindracea. Dormo et al. ${ }^{16}$ construíram um sistema com pervaporação para ser utilizado na remoção da água produzida na reação de esterificação do óleo fúsel com ácido oleico catalisada pela lipase Novozym® 435. Nas condições otimizadas o sistema foi adequado para obter elevadas conversões $(99,8 \%)$ em 6 h de reação.

Desta forma, verifica-se que os resultados descritos no presente trabalho se comparam favoravelmente com os descritos na literatura, em termos de conversão em éster nas condições empregadas (ausência de solventes, utilização de suporte não comercial e ausência de estratégia para remoção da água formada como subproduto).

\section{Avaliação sensorial dos ésteres formados durante as reações de esterificação}

Além da pureza das amostras e teor do componente de interesse (éster), diversas características físico-químicas e sensoriais são fundamentais para a aceitação de um produto pelo consumidor. Estas características são comumente avaliadas por técnicas de análise sensorial. A avaliação sensorial é uma medida qualitativa baseada em informações recebidas pelos sentidos humanos..$^{23}$ Esta medida é muitas vezes realizada em painéis de análise sensorial, nos quais pessoas são empregadas para avaliar as características do produto. ${ }^{33,34}$ Métodos sensoriais de medida, no entanto, apesar de serem muito importantes e largamente empregados, parecem perder a precisão desejável em pesquisa científica em função da variabilidade inerente à avaliação individual de cada pessoa envolvida. Assim, o emprego de equipamentos capazes de realizar medidas mais objetivas e que possam pelo menos complementar a análise tradicional na avaliação da qualidade de produtos alimentícios é desejável. Neste caso, o uso de sensor olfativo artificial mostra-se como uma técnica promissora, pois permite detectar os diferentes aromas presentes no produto final, bem como monitorar a uniformidade e consistência dos aromas formados durante o processo. ${ }^{34}$ Desta forma, os aromas dos três componentes, ácido caprílico, óleo fúsel e ésteres formados pela esterificação do ácido caprílico com óleo fúsel foram avaliados pelos sensores gerando o perfil mostrado na Figura 4.

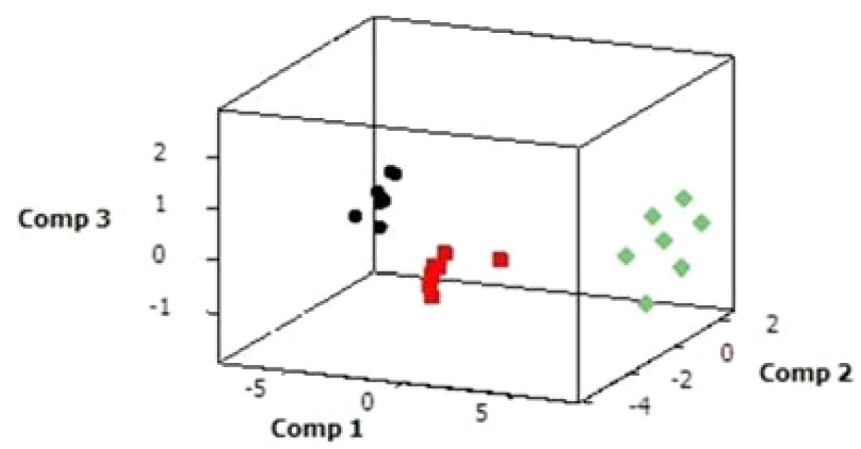

Figura 4. Perfil dos aromas dos ésteres obtidos (quadrado vermelho) e dos materiais de partida na esterificação do ácido caprílico (círculo preto) com óleo fúsel (losango verde)

O perfil permite a comparação dos aromas entre os materiais de partida e os produtos formados nas sínteses de ésteres. Verifica-se que os ésteres formados apresentaram aromas diferentes dos materiais de partida. Os ésteres são representados na cor vermelha, na região central da figura, ao seu lado esquerdo tem-se o ácido caprílico representado na cor preta, e ao seu lado direito tem-se o óleo fúsel na cor verde. Desta forma, é possível afirmar que ocorreram mudanças nos aromas dos materiais de partida antes e após as reações de esterificação.

Verifica-se ainda que o perfil do aroma referente ao óleo fúsel apresentou grande espalhamento, o que pode estar associado à composição mista de alcoóis presentes nesta matéria-prima. O mesmo comportamento foi observado para os aromas dos ésteres formados, porém em menor grau. Por outro lado, este comportamento não foi observado no caso do ácido caprílico por se tratar de reagente puro. Os componentes (1,2 e 3) explicam juntos 96,68\% das variações ocorridas entre as amostras, demonstrando que os sensores discriminaram as amostras satisfatoriamente.

\section{CONCLUSÃO}

O presente trabalho teve como enfoque sintetizar ésteres a partir da matéria-prima residual óleo fúsel utilizando lipases como catalisadores e como doador do grupo acila o ácido caprilico. Mediante testes de seleção de fontes de lipases microbianas, foi selecionada a lipase $R$. oryzae com potencial para aplicação na síntese do caprilato de isopentila resultando em elevadas conversões em $24 \mathrm{~h}$ de reação. As condições reacionais da síntese de ésteres utilizando óleo fusel foram estabelecidas por planejamento experimental, avaliando o efeito das variáveis: temperatura e razão molar ácido/ álcool. A análise dos resultados revelou que a formação do caprilato de isopentila foi influenciada somente pela variável razão molar ao nível de $95 \%$ de confiança. O modelo matemático proposto permitiu prever as condições que favorecem o alcance de elevados rendimentos de formação do éster, sendo a reação maximizada (82\% em 24 h) para meios reacionais constituídos de óleo fúsel e ácido caprílico na razão molar de $1: 5$ e temperatura de $45^{\circ} \mathrm{C}$. O perfil sensorial efetuado pelo nariz eletrônico permitiu uma comparação dos aromas entre materiais de partida e os produtos formados, sendo constatado que os ésteres formados apresentaram aromas bem distintos dos materiais de partida, sugerindo que ocorreram mudanças nos aromas dos materiais de partida antes e após as reações de esterificação. 


\section{MATERIAL SUPLEMENTAR}

Os espectros de $\mathrm{RMN}^{1} \mathrm{H}$, bem como a análise das estruturas dos padrões cromatográficos utilizados neste trabalho, estão disponíveis em http://quimicanova.sbq.org.br, na forma de arquivo PDF, com acesso livre.

\section{AGRADECIMENTOS}

Os autores agradecem o apoio financeiro concedido pela CAPES (Coordenação de Aperfeiçoamento de Pessoal de Ensino Superior) e CNPq (Conselho Nacional de Desenvolvimento Científico e Tecnológico).

\section{REFERÊNCIAS}

1. Calam, A.; Solmaz, H.; Uyumaz, A.; Polat, S.; Yilmaz, E.; Içingur, Y. J.; Energy Inst. 2015, 88, 3, 258.

2. Berger, R. G.; Krings, U.; Zorn, H. In Food Flavour Technology; Taylor, A. J., Linforth, R. S. T., eds.; Wiley-Blackwell: Oxford, 2010. p. 89-115.

3. Ferreira, M. C.; Meirelles, A. J. A.; Batista, E. A. C.; Ind. Eng. Chem. Res. 2013, 52, 2336.

4. Basso, L. C.; Basso, T. O.; Rocha, S. N. In Biofuel Production-Recent Developments and Prospects; Bernardes, M. A. S., eds.; Intech: Croatia, 2011, pp. 85-100.

5. Mhetras, N.; Patil, S.; Gokhale, D.; Indian J. Microbiol. 2010, 50, 432.

6. Sun, J.; Chin, J. H.; Zhou, W.; Yu, B.; Curran, P.; Liu, S. Q.; J. Am. Oil Chem. Soc. 2012, 89, 1991.

7. Sun, J.; Yu, B.; Curran, P.; Liu, S. Q.; Food Chem. 2013, 141, 2828.

8. Khan, N. R.; Rathod, V. K.; Process Biochem. 2015, 50, 1793.

9. Stergiou, P. Y.; Foukis, A.; Filippou, M.; Koukouritaki, M.; Parapouli, M.; Theodorou, L. G.; Hatziloukas, E.; Afendra, A. M.; Pandey, A.; Papamichael, E.; Biotech. Advances 2013, 31, 1846.

10. Choi, J.; Han, S.; Kim, H.; Biotechnol. Adv. 2015, 33, 1443.

11. Dhake, K. P.; Thakare, D. D.; Bhanage, B. M.; Flavour Fragr. J. 2013, 28,71 .

12. Macedo, G. A.; Pastore, G. M.; Ciênc. Tecnol. Aliment. 1997, 17, 115.

13. De Castro, H. F.; Moriya, R. Y.; Oliveira, P. C.; Soares, C. M. F.; Appl. Biochem. Biotechnol. 1999, 77/79, 827.

14. Anschau, A.; Aragão, V. C.; Porciuncula, B. D. A.; Kalil, S. J.; Burkert, C. A. V.; Burkert, J. F. M.; J. Braz. Chem. Soc. 2011, 22, 2148.
15. Güvenç, A.; Kapucu, N.; Kapucu, H.; Aydogan, O.; Mehmetoglu, U.; Enzyme Microb. Technol. 2007, 40, 778.

16. Dormo, N.; Belafi-Bako, K.; Bartha, L.; Ehrenstein, U.; Gubicza, L.; Biochem. Eng. J. 2004, 21, 229.

17. Castro, H. F.; Anderson, W. A.; Quim. Nova 1995, 18, 544.

18. Rajendran, A.; Palanisamy, A.; Thangavelu, V.; Braz. Arch. Biol. Technol. 2009, 52, 207.

19. Bruno, L. M.; de Lima Filho, J. L.; Melo, E. H. M.; de Castro, H. F.; Appl. Biochem. Biotechnol. 2004, 113, 189.

20. Santos, J. C.; Bueno, T.; Da Rós, P. C. M.; De Castro, H. F.; J. Chem. Technol. Biotechnol. 2007, 82, 956.

21. Rodrigues, M. I.; Iemma, A. F.; Planejamento de experimentos $e$ otimização de processos: Uma estratégia sequencial de planejamentos, 1 ed., Editora Casa do Pão: Campinas, 2005, 326p.

22. Giordani, D. S.; Siqueira, A. F.; Silva, M. L. C. P.; Oliveira, P. C.; De Castro, H. F.; Energ. Fuel 2008, 22, 2743.

23. Röck F.; Barsan N.; Weimar U.; Chem. Rev. 2008, 108, 705.

24. Urioste, D.; Castro, M. B. A.; Biaggio, F. C.; De Castro, H. F. Quim. Nova 2008, 31, 407.

25. Martin, L. S.; Santos, F. D.; Oliveira, P. C.; De Castro, H. F.; XXI Congresso Brasileiro de Engenharia Química, Fortaleza, Brasil, 2016.

26. Soares, C. M. F.; De Castro, H. F.; Moraes, F. F.; Zanin, G. M.; Appl. Biochem. Biotechnol. 1999, 77, 745.

27. Paula, A. V.; Nunes, G. F. M; Silva, J. L.; De Castro, H. F.; Santos, J. C.; Appl. Biochem. Biotechnol. 2010, 160, 1146.

28. Paula, A. V.; Nunes, G. F; De Castro, H. F.; Santos, J. C.; Ind. Eng. Chem. Res. 2015, 54, 1731.

29. Paula, A.V.; Nunes, G. F. M.; Osório, N. M.; Santos, J. C.; De Castro, H. F.; Ferreira-Dias, S. Eur. J. Lipid Sci. Technol. 2015, 117, 608.

30. Laane, C.; Boeren, S.; Vos, K.; Veeger, C.; Biotechnol. Bioeng. 1987, 30, 81.

31. Welsh, F. W.; Williams, R. E. J.; Food Sci. 1989, 54, 1565.

32. De Castro, H. F.; Moriya, R. Y.; Ribeiro, R. R.; In: XVII Simpósio IberoAmericano de Catálise, FEUP Edições: Porto, 2000, 1, 793.

33. Meilgaard, M. C.; Carr, B. T.; Civille, G. V.; Sensory evaluation techniques; CRC press, 2006.

34. Tiggemann, L.; Ballen, S.; Bocalon, C.; Graboski, A. M.; Manzoli, A.; Herrmann, P. P. S.; Steffens, J.; Valduga, E.; Steffens, C.; J. Food Eng. 2016, $180,16$. 